\title{
Comparative Strength and Cost of Rice Husk Concrete Block
}

\author{
Setya Winarno ${ }^{1, *}$ \\ ${ }^{1}$ Master Program of Civil Engineering, Universitas Islam Indonesia
}

\begin{abstract}
This research presents a comparative cost and strength analysis of rice husk concrete block which is aimed at reducing the cost of concrete production and emphasizing environmentally and friendly sustainable materials. Concrete block materials consist of cement, filler, and rice husk. Tests were performed to compare the strength and cost of seven cement rice husk weight ratios designated ranging from 0.67 to 2.00 with constant water cement ration of 0.4 . Samples have been tested for 28-day strength. The analysis of the results has showed that the higher proportions of rice husk correspond to decreased strength dan cost polynomially. At $134 \%$ proportion of rice husk, it is optimum value for rice husk concrete block. In this point, the compressive strength satisfies the standard. Also, water absorption of $16,04 \%$ justifies the maximum standard. Overall, the cost of $134 \% \mathrm{RH}$ concrete is $\mathrm{Rp} 511,809$ per $\mathrm{m}^{3}$ which is $42.5 \%$ cheaper than normal concrete block.
\end{abstract}

\section{Introduction}

Due to rapid expansion of construction and infrastructure activities in Indonesia, the demand of the construction materials such as timbers, concretes, bricks, and steels are increasing. The rising cost of construction raw material and production are common in Indonesia due to Indonesian economic and financial upheaval. On the same time, such buildings and infrastructures in Indonesia have to be built with good quality to withstand against many types of disaster, especially earthquakes. In line with the current issue of sustainability, the high demand for concrete in construction and building industries, the use of conventional aggregates has drastically grown up and reduced the natural stone deposits thereby; causing an ecological imbalance of the environment. According to the above four reasons, there is a need for alternative system to fulfil the construction material demand in term of its quality and affordability. There is a need to explore other suitable materials to replace or substitute the conventional concrete material.

Currently, the focal challenges facing the building and housing sector are highlighted and emphasised on the reduction of environmental impact. In this context, an environmentally and friendly sustainable materials using renewable and indigenous resources are in full development. Over the last years, a large number of researches have been addressed towards the utilisation of waste materials, particularly agriculture waste, for

*Corresponding author: winarno@uii.ac.id 
eco-concrete. Broadly speaking, concrete is a very widely used material because the constituents of concrete are easily obtained. Examples of studied eco-concrete materials are hemp [5-7] [1] and bagasse fibres [3]. As it is fundamental to select carefully the raw materials to design in sustainable manner, it makes sense to create interesting links between agriculture waste and construction industry. Concrete made by agriculture waste provides an excellent lightweight material because of the interconnected network of porosity which characterizes these materials.

In Indonesian construction industry, the use of concrete block is very popular due to the shortage of fired clay bricks. Concrete blocks are one of components of durable masonry construction. Concrete blocks are stacked one at a time and held together with fresh concrete mortar to form the desired length and height of the wall. Usually, they consist of high mass materials with good compressive strength formed into units that can be lifted and handled by a single worker. For earthquake structure purposes, it is focused on the lighter materials that can reduce significantly the earthquake load. Concrete blocks which are made by mixed Portland Cement (PC) and agriculture waste will provide lighter concrete blocks because there are a lot of porosity inside agriculture waste which contributes significantly for its weight. It seems clear that the mechanical properties of these agriculture waste-based concrete blocks may be considered as the main weakness point. Indeed, this concrete block cannot be used as full load-bearing materials. Moreover, they are more porous than conventional concrete blocks and must be sealed to prevent water penetration.

One of the agriculture wastes is rice husk. Rice husks, sometimes called rice hulls, are the shells produced during the husking operation of paddy rice. Rice husks can be considered as agro-industrial by-products coming from the rice hulling. Due to the low nutritional ingredient of rice-husk, it is not appropriate for use as a feed for animals. Moreover, its siliceous composition is resistant to natural degradation, which can produce a large environmental load [8]. Hence, adequate alternative disposal arrangements must be considered to avoid environmental effects. Rice husk constitutes $20 \%$ of the 500 million tons of paddy produced in the world [2]. In Indonesia only, there were 81,38 million tons of paddy in 2017 [4]. Hence, rice farming produces nearly 16 million tons per year of rice husk in Indonesia. It is clear that the use of rice husk decreases the demand for aggregate in the construction industry, reduces the cost of concrete production, and reduces the negative environmental impact. This large amount of rice husk in Indonesia is very challenging for concrete block aggregate. At the same time, project owners and project teams are increasingly facing shorter schedules and tighter budgets. The objectives of this paper are to (1) analyse the strength of various types of concrete blocks with additional rice husk, and (2) carry out cost analysis on various types of concrete blocks.

\section{Methodology}

Rice husks correspond to the protective shell of the rice grain. The rice husk is provided from the Sleman District, Yogyakarta Province of Indonesia. This experience was held in Innovation Centre of Universitas Islam Indonesia, Sleman, Yogyakarta. The materials of concrete block consist of Portland Cement (PC), rice husk, and filler. Utilisation of rice husk is as sand replacement. The filler is very fine sand (VFS) which is stone waste generated from cutting stone blocks into slabs using stone block cutting machine. This type of VFS is in the form of very fine stone particles with approximate diameter of $0.10-0,05$ $\mathrm{mm}$. Seven various sand replacement were used. There are two parameters which are investigated in this study, i.e. strength dan cost. The strength corresponds to compressive strengths and the cost is related to the optimum economic benefit of adding rice husk into concrete block mixing. 


\section{Concrete Block}

Currently, a concrete block is largely used as a building material in the construction of walls. It is sometimes called a concrete masonry unit. A concrete block is one of numerous precast concrete products used in construction in which they are formed and hardened before they are brought to the construction site. There are two types of concrete block, i.e. solid block and hollow block, and their sides may be cast smooth or with a design. The inside hollow blocks are to allow for steel bars and mortar filling. One unit of concrete block can be lifted and handled by a single worker. In the construction of walls, like bricks, concrete blocks are laid in courses with fresh concrete mortar as the bed and binding material to form the planned length and height of the wall. In Sleman District area, hundreds of thousands of these houses were built using concrete blocks, probably because the raw materials needed to make concrete blocks were in abundant supply in sand banks throughout this region.

These early blocks were usually made conventionally, cast by hand, and the average output was about 10-15 blocks per person per hour. By not requiring firing, each unit can be manufactured on site by unskilled masons. Currently, concrete block manufacturing is an extremely automated process. In Sleman District area, medium concrete plants with common small machine can produce up to 100 blocks per hour. The constituents commonly used to make concrete blocks are a mixture of powdered Portland Cement (PC), water, and sand. PC refers to bonding agents that are mixed with water to produce a cementing paste. Water plays an important role in the production of concrete. Water and PC will blend together through chemical reaction and produce cement paste to fill the voids in the concrete. The water converts the dry concrete and sand into plastic and workable form. Hardening occurs because of this chemical reaction, called hydration. It is well known that the strength of concrete is closely dependent upon the water/cement ratio (w/c). The production of concrete block needs $\mathrm{w} / \mathrm{c}$ about 0.4 , in which it generates relatively dry and stiff mixture concrete.

This mixture produces a light block with a medium-to-coarse surface texture and good compressive strength. The shapes and sizes of most common concrete blocks have been standardized to ensure uniform building construction. The most common block size in Indonesia is with the nominal measurements of $18-20 \mathrm{~cm}$ high, by $9-10 \mathrm{~cm}$ deep, and by $36-40 \mathrm{~cm}$ wide. A typical concrete block weighs $10-14 \mathrm{~kg}$. In general, the concrete mixture used for blocks has a higher percentage of sand and a lower percentage water than the concrete mixtures used for general structural construction purposes. The fresh block emerging from mould is a very dry and stiff mixture that it holds its shape when it is removed from the block mould.

In general, the production of concrete blocks in medium concrete plants consists of three basic processes: mixing, moulding, and curing. Some manufacturing plants produce only concrete blocks, while others may produce a wide variety of precast concrete products including paving blocks, concrete roof, and decorative landscaping pieces. Broadly speaking, its manufacture consists of 3 processes as follows.

1. Mixing: After weighing, the appropriate amounts of water, sand, and dry cement are mixed homogenously and then water is added. For better results, mixer machine is used thorough mixing process.

2. Moulding: In a specialized machine, the mixture is compacted on moulds that define the shape and size. The machine is equipped with mechanical vibrations, making the concrete block more compact.

3. Curing: As the fresh blocks emerge from the block machine, the blocks are put in shady place to harden. The fresh blocks are kept away from sunshine directly. The following day, the blocks are stacked in stock pile and then, they are poured with fresh 
water to make chemical process between PC and water is running well. For modern concrete plants, the blocks are placed in steam ovens (low or high pressure) to harden.

The manufacture of concrete blocks requires systematic quality control along the three processes above to produce blocks that have the required properties. The process of curing through watering is to ensure that the blocks are cured properly, in order to achieve their required strength. Besides the quality control, the simple concrete block will continue to evolve as architects and block manufacturers incorporate their creativity in developing new shapes and sizes. These new blocks promise to make building construction faster, lighter, and less expensive.

Usually, conventional concrete block is made of a mixture of powdered Portland Cement (PC), water, and sand. Ratio a cement-sand mixture is $1: 7,1: 8$, or 1:9, with a maximum size sand (with coarse sand) of $10 \mathrm{~mm}$. One unit of block can weigh about 12-14 $\mathrm{kg}$. It means that for structure which is constructed by using normal concrete block, its selfweight represents a very large proportion of the total dead load on the structure. In order to reduce earthquake load, the total dead load of the structure has to be reduced. This can be achieved through replacing conventional concrete block to lightweight concrete block. Lightweight concrete is associated with the main properties of its ingredients that are low density. Lower in density leads to reduction in weight and this means reduction in the total load. With the purpose of lightweight concrete, sand (as the main ingredient for concrete block) will be replaced with rice husk.

\section{Rice Husk (RH)}

Rice husk (RH) has been long considered an agriculture waste from the rice milling process. It is the coating on a seed or grain of rice (Figure 1). Many people in Sleman District area are rice farmer, thus, RH can be easily collected and is cheap. It is often dumped and/or burned. Each $\mathrm{kg}$ of milled white rice results in roughly $0.20 \mathrm{~kg}$ of rice husk as a by-product of rice production during milling. In Indonesia, there were 81.38 million tons of rice in 2017 . Hence, rice farming produces nearly 16 million tons per year of RH in Indonesia.

$\mathrm{RH}$ is formed from hard materials, including silica and lignin, to protect the seed during the growing season. It is resistant to natural degradation, in which adequate alternative disposal arrangements must be considered to avoid environmental effects. RH husk is in loose form that can substitute fine aggregate in the construction industry, reduce the cost of concrete production, and reduce the negative environmental impact. This large amount of $\mathrm{RH}$ in Indonesia is very interesting to replace sand for concrete block

Fig. 1. Rice husk (RH)

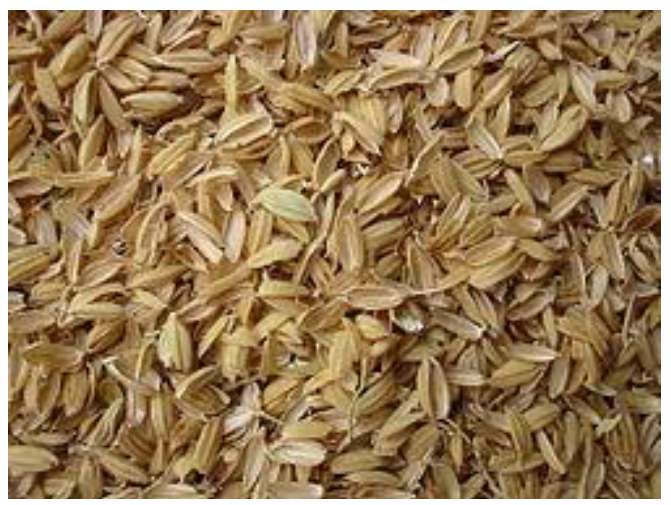


The utilisation of RH for eco-concrete is an environmentally and friendly sustainable materials on the reduction of environmental impact. $\mathrm{RH}$ as aggregate is used in condition of saturated surface dry (SSD). SSD is defined as the condition of RH in which the surfaces of the particles are "dry" (i.e., surface adsorption would no longer take place), but the interparticle voids are saturated with water. In this condition RH will not affect the free water content of a concrete mixture. Concrete made by $\mathrm{RH}$ provides an outstanding lightweight concrete because of the interconnected network of porosity which characterizes these materials. Structure with lightweight materials is very suitable for constructions in earthquake prone areas. Moreover, lightweight buildings are recommended to be built in poor soil conditions, hence saving in structural foundation costs.

The characteristics of RH is lighter than sand. It is estimated at $690 \mathrm{~kg} / \mathrm{m} 3$ by Salas Serrano and Veras Castro [8], while the weight of sand can reach at about $1800 \mathrm{~kg} / \mathrm{m} 3$. Particle size distribution was investigated on RH aggregates. Rice husks width ranges from 2 to $4 \mathrm{~mm}$ and the maximum length is about $10 \mathrm{~mm}$. It is relatively homogenous in particle size distribution.

$\mathrm{RH}$ can produce a uniform distribution of air voids throughout the concrete mixture. At last, one unit of RH concrete block can only weigh $7-8 \mathrm{~kg}$ (about $42 \%$ lighter) that has a low-density concrete compare to the normal concrete. The lightweight RH concrete block is a new technology made in order to facilitate various constructions and save time for the constructor. This versatile material is a revolutionary non-structural construction material much needed for quality housing, modern high-rise buildings with framed structures etc. Figure 2 depicts RH concrete block.

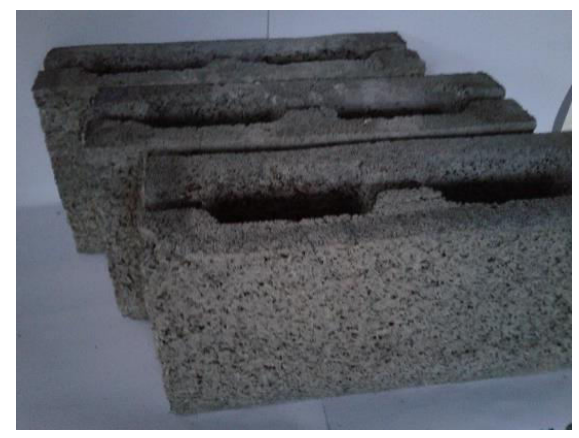

(a)

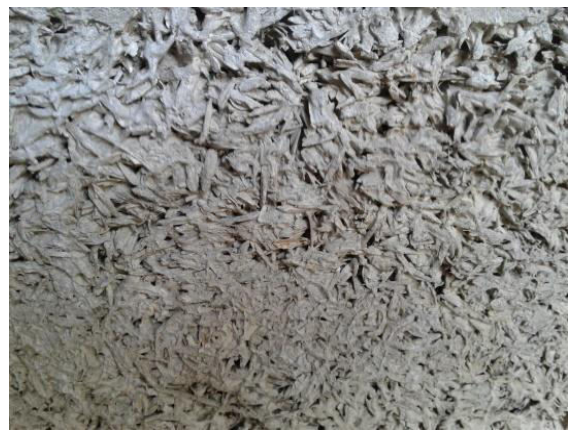

(b)

Fig. 2. Rice husk concrete block

(a) Three units concrete block (b) The surface texture of concrete block

\section{Filler}

In this study, the ingredients of the concrete block are PC, RH, and filler. The fillers are very fine sand (VFS) added to concrete to better some properties of the mixtured material and also to lower the consumption of PC. The VFS is stone particles waste generated from cutting Merapi stone blocks into slabs using stone block cutting machine. Merapi is one of the most active volcanoes in Java and is located in Sleman District area, less than $30 \mathrm{~km}$ north of Yogyakarta, the tourist destination city in Central Java, Indonesia with a population of about 3,5 million. In Sleman, there are many stone cutting industries. Stone cutters produce waste materials (stone particles) that can damage the sanitary sewer system or pollute our local creeks. Poor practices in stone cutter industry can cause contaminants to pollute our local creeks and sewer system causing harm to the public and the environment. It is important to reduce the industry's adverse impact on the downstream agricultural land 
and the adverse impact on the drinking water aquifers. Table 1 provides physical properties of VFS.

Table 1. Physical properties of VFS as filler

\begin{tabular}{|l|c|}
\hline \multicolumn{1}{|c|}{ Physical test } & Values \\
\hline Specific gravity & 2.41 \\
\hline Fineness modulus & 2.09 \\
\hline Diameter $(\mathrm{mm})$ & $0.10-0.04$ \\
\hline Bulk density $\left(\mathrm{kg} / \mathrm{m}^{3}\right)$ & 1224 \\
\hline
\end{tabular}

\section{Concrete Mixture}

Usually, concrete blocks are often made of mixture PC and sand with a ratio of 1:7, 1:8, or 1:9 fundamentally. The maximum size of sand is $10 \mathrm{~mm}$. For this study purpose, ingredients of concrete blocks are PC, filler, and $\mathrm{RH}$. Based on filler purpose, the weight ratio of PC to filler of all concrete blocks was kept to about 1:0.25 throughout the whole experimental works. Also, overall mixtures were decided to use w/c 0.4, to generate stiff mixture concrete.

Table 2. Concrete mixture proportions

\begin{tabular}{|c|c|c|c|c|c|c|c|}
\hline \multirow[t]{2}{*}{ Mix } & \multicolumn{4}{|c|}{ Proportions by weight } & \multicolumn{3}{|c|}{ Proportions by volume } \\
\hline & $\mathrm{PC}^{*}$ & Filler** & $\mathrm{RH}^{* * *}$ & $\begin{array}{c}\text { Percentage of } \\
\text { RH to PC }\end{array}$ & $\mathrm{PC}^{*}$ & Filler** & $\mathrm{RH}^{* * *}$ \\
\hline V1 & 1 & 0.25 & 0.67 & $67 \%$ & 1 & 0.63 & 3 \\
\hline V2 & 1 & 0.25 & 0.89 & $89 \%$ & 1 & 0.63 & 4 \\
\hline V3 & 1 & 0.25 & 1.11 & $110 \%$ & 1 & 0.63 & 5 \\
\hline V4 & 1 & 0.25 & 1.34 & $134 \%$ & 1 & 0.63 & 6 \\
\hline 'V5 & 1 & 0.25 & 1.56 & $156 \%$ & 1 & 0.63 & 7 \\
\hline V6 & 1 & 0.25 & 1.78 & $178 \%$ & 1 & 0.63 & 8 \\
\hline V7 & 1 & 0.25 & 2.00 & $200 \%$ & 1 & 0.63 & 9 \\
\hline
\end{tabular}

$\mathrm{RH}$ in this concrete is as a sand replacement. In total, there are seven $\mathrm{PC} / \mathrm{RH}$ weight ratios designated ranging from 0.67 to 2.00 . Equally, the volume ratio of $\mathrm{PC} / \mathrm{RH}$ can be expressed ranging from 3 to 9 . This volume ratio aims to simplify and ease the proportion measurement among concrete ingredients during laboratory mixing test. Condition of RH and filler are based on saturated surface-dry (SSD). This is achieved under laboratory conditions when all the pores are completely filled with water, but no free water remains on the surface of the materials. $\mathrm{RH}$ and filler in this condition will not contribute free water nor absorb water from the mix. Table 2 describes the concrete mix proportions.

\section{Strength and Cost of Concrete Blocks}

Compressive strength of concrete block test provides an idea that whether concreting has been done properly or not. These specimens are tested by compression testing machine after 28 days curing. Load should be applied gradually at the rate of $140 \mathrm{~kg} / \mathrm{cm} 2$ per minute to cause fracture of the specimens. Load at the failure divided by area of specimen gives the compressive strength of concrete. This strength depends on many factors such as watercement ratio, quality and proportion of concrete material, and production method. According to Indonesian Standard SNI 03-0349-1989 (concrete block for wall structure): compressive strength minimum for solid and hollow concrete block are $20 \mathrm{~kg} / \mathrm{cm}^{2}$ and 17 
$\mathrm{kg} / \mathrm{cm}^{2}$ respectively. Another test in SNI 03-0349-1989 is water absorption. Concrete block lies in 8 hours immersion in water, and the percentage weight increase of concrete block is the value of water absorption. Water absorption maximum is $35 \%$ for both.

This study investigates seven varieties of concrete mixture while $\mathrm{RH}$ is as a sand replacement. Each variety consists of three specimens. The results of strength and water absorption are mentioned in Table 3.

Table 3. Compressive strength and water absorption

\begin{tabular}{|c|c|c|c|c|c|c|c|c|c|}
\hline \multirow[t]{2}{*}{ Mix } & \multirow{2}{*}{\begin{tabular}{|c|} 
Percentage \\
of RH to \\
PC
\end{tabular}} & \multicolumn{4}{|c|}{ Strength $\left(\mathrm{kg} / \mathrm{cm}^{2}\right)$} & \multicolumn{4}{|c|}{ Water absorption (\%) } \\
\hline & & $\# 1$ & $\# 2$ & $\# 3$ & Average & $\# 1$ & $\# 2$ & $\# 3$ & Average \\
\hline V1 & $67 \%$ & 19.40 & 19.56 & 19.35 & 19.44 & 14.27 & 13.93 & 14.43 & 14.21 \\
\hline V2 & $89 \%$ & 19.20 & 18.90 & 18.97 & 19.02 & 14.89 & 15.01 & 14.72 & 14.87 \\
\hline V3 & $110 \%$ & 18.67 & 18.87 & 18.30 & 18.61 & 15.49 & 15.78 & 15.47 & 15.58 \\
\hline V4 & $134 \%$ & 17.67 & 17.87 & 17.22 & 17.59 & 16.03 & $\begin{array}{l}15.99 \\
\end{array}$ & 16.09 & 16.04 \\
\hline V5 & $156 \%$ & 14.37 & 14.20 & 14.57 & 14.38 & 19.27 & 18S.97 & 18.87 & 19.04 \\
\hline V6 & $178 \%$ & 11.30 & 11.70 & 11.53 & 11.51 & 21.56 & 21.67 & 22.03 & 21.75 \\
\hline V7 & $200 \%$ & $*$ & $*$ & $*$ & $*$ & $*$ & $*$ & $*$ & $*$ \\
\hline
\end{tabular}

*) Fresh concrete block variety number 7 (V7) is too stiff and too fragile when it removes out from its mould. Thus, V7's concrete block is deleted from analysis.

Besides strength, this study is also scrutinised cost of concrete production. Cost of concrete production is an important aspect. In particular, it is for large construction projects where quantity of concrete consumption is huge. Benefits of understanding of this cost is that it provides the right proportions of materials, thus making the concrete construction economical in achieving required strength of structural members. Raw materials are the basis for costing of all concrete productions.

Table 4. Overall cost and density for $1 \mathrm{~m} 3$ of concrete mixture

\begin{tabular}{|c|c|c|c|c|c|c|}
\hline Mix & Percentage of & \multicolumn{3}{|c|}{ Proportions by weight, $\mathrm{kg}$} & Cost of $1 \mathrm{~m}^{3}$ & Density, \\
& RH to PC & PC & Filler & RH & & $\mathrm{kg} / \mathrm{m}^{3}$ \\
\hline V1 & $67 \%$ & 637 & 159.25 & 425.35 & Rp 784,402 & 1221.60 \\
\hline V2 & $89 \%$ & 528 & 132.00 & 470.09 & Rp 662,096 & 1130.09 \\
\hline V3 & $110 \%$ & 451 & 112.75 & 501.92 & Rp 575,711 & 1065.67 \\
\hline V4 & $134 \%$ & 394 & 98.50 & 526.18 & Rp 511,809 & 1018.68 \\
\hline V5 & $156 \%$ & 349 & 87.25 & 543.76 & Rp 461,258 & 980.01 \\
\hline V6 & $178 \%$ & 314 & 78.50 & 559.12 & Rp 422,050 & 951.62 \\
\hline V7 & $200 \%$ & 285 & 71.25 & 570.92 & Rp 389,504 & 927.17 \\
\hline
\end{tabular}

Table 2 has mentioned the estimated amount of raw materials needed to complete production. This is never an exact science. There is always going to be some margin of error in determining the precise amount. Based on survey for ten construction material outlets in Sleman District area, cost of PC is Rp 45.000/zak (40 kg) or about Rp 1.125/kg. As $\mathrm{RH}$ and filler are waste product, they are just left in piles or thrown into pits and also free of charge if someone collects them. Sometimes, people can utilise filler as landfill and $\mathrm{RH}$ for clay brick burning. For this study, the true cost of RH and filler includes a number of associated costs, such as: cost of purchasing sacks, cost of collection, cost of handling, cost of transportation, and cost of maintenance. Based on several investigations and basic calculation, the cost of RH and filler is about $\mathrm{Rp} 95 / \mathrm{kg}$ and $\mathrm{Rp} 65 / \mathrm{kg}$ respectively and $\mathrm{Rp}$ $25.000 / \mathrm{m}^{3}$ for labour cost. Overall, the cost for $1 \mathrm{~m}^{3}$ of concrete mixture is described in Table 4. 


\section{Discussion}

Based on Table 3 and 4, Figure 3 describes the trend line of strength and cost among six different proportions of $\mathrm{RH}$.

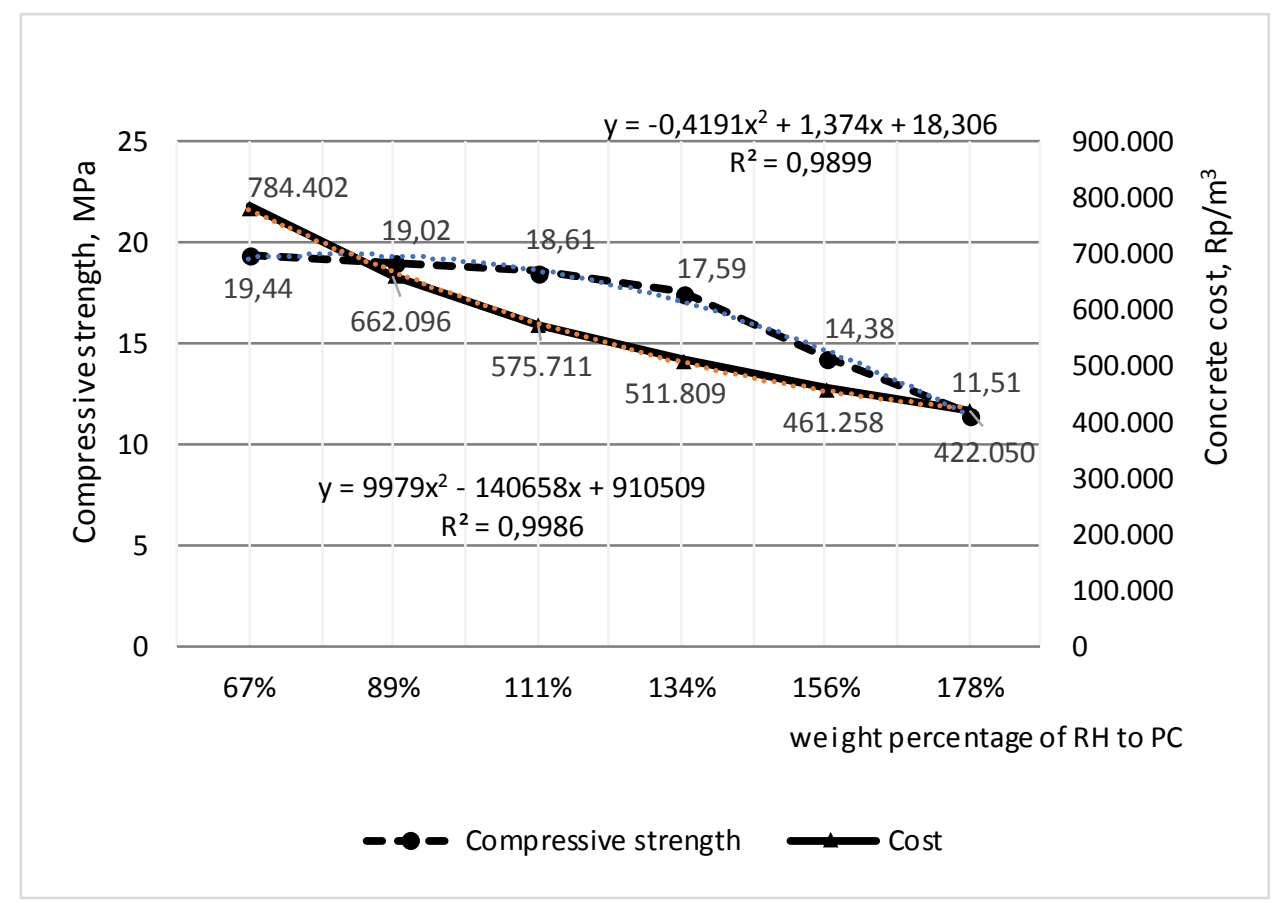

Fig. 3. Compressive strength (at 28 days) and cost gained for different percentage of RH

Results obtained from six different proportions of $\mathrm{RH}$ have showed that the concrete cost decreased polynomially, with equation: $y=9979 x 2-140658 x+910509$, in which $y=$ cost and $\mathrm{x}=$ weight percentage of RH to PC. Similar result is also achieved in strength, with equation: $y=-0.419 \times 2+1.374 x+18.306$. In relation to the strength, it decreases more significantly after $134 \%$ of RH, in which this point gets the strength of $17.59 \mathrm{~kg} / \mathrm{cm}^{2}$. This strength value is still fulfilled SNI Standard for concrete block, i.e. $17 \mathrm{~kg} / \mathrm{cm}^{2}$. Similar result has been described in Figure 4, in particular for water absorption. The percentage of $134 \%$ gives clear understanding that after this point water absorption is increasing significantly. All of the variations satisfy the maximum standard of water absorption, i.e. $35 \%$. 

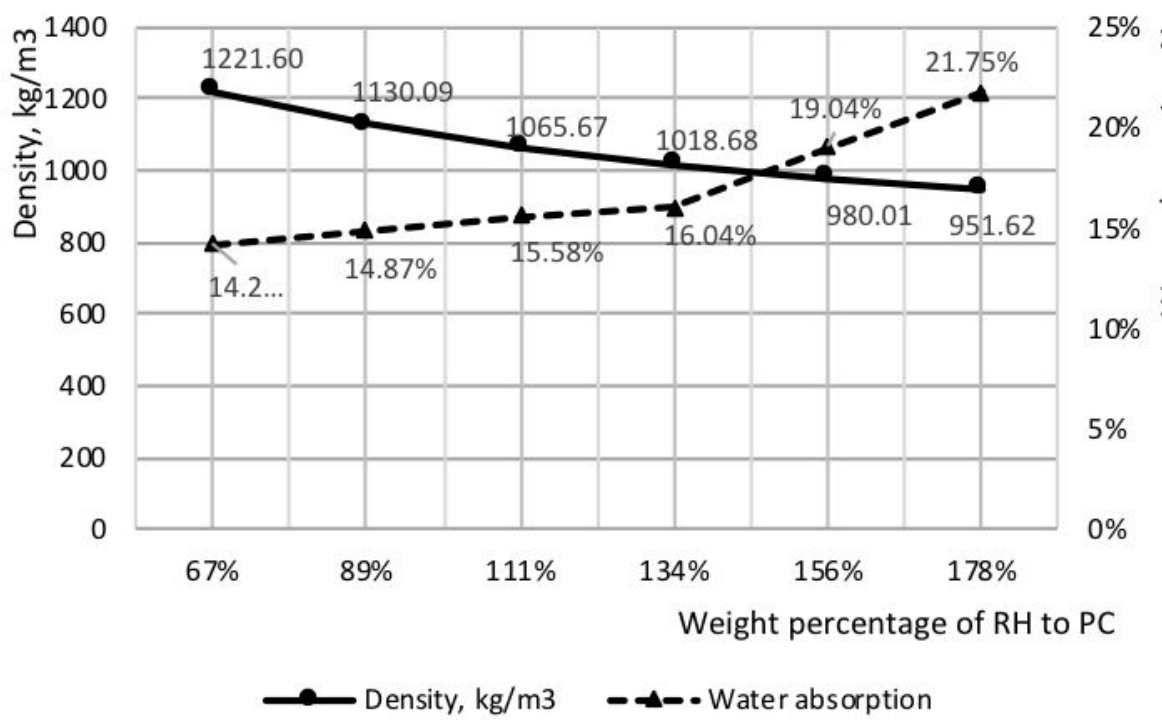

Fig. 4. Density and water absorption gained for different percentage of RH

The trend of cost and density in Figure 3 and 4 are decreasing linearly. Taking a look at $134 \%$ of $\mathrm{RH}$, the density is $1018.68 \mathrm{~kg} / \mathrm{m}^{3}$ which is $46.30 \%$ lighter to normal concrete block, i.e. $2,200 \mathrm{~kg} / \mathrm{m}^{3}$. This $134 \%$ of RH concrete can be classified as lightweight concrete category which has density range $300 \mathrm{~kg} / \mathrm{m} 3$ up to $1840 \mathrm{~kg} / \mathrm{m}^{3}$.

\section{Conclusions}

Among seven variations, it can be concluded that $134 \%$ of $\mathrm{RH}$ is optimum value for RH concrete block. In this point, the compressive strength satisfies the standard. Also, water absorption of $16,04 \%$ justifies the maximum standard. Overall, the cost of $134 \% \mathrm{RH}$ concrete is $\mathrm{Rp} 511,809$ per $\mathrm{m}^{3}$ which is $42.5 \%$ cheaper than normal concrete block, i.e. $\mathrm{Rp}$ 890,000 . As RH is lightweight material, it is important to search further thermal insulation and acoustic insulation for this RH concrete block.

\section{References}

1. L. Arnaud, E. Gourlay, Experimental study of parameters influencing mechanical properties of hemp concretes, Constr Build Mater, 28, 50 (2012)

2. N. Bhanumathidas, P.K. Mehta, Concrete mixtures made with ternary blended cements containing fly ash and rice husk ash. In V. M. Malhotra (Ed.), International conference proceeding seventh CANMET Chennai, India, 1, 199 (2004)

3. K. Bilba, M.A. Arsene, Silane treatment of bagasse fiber for reinforcement of cementitious composites, Compos A Appl Sci Manuf, 39, 95 (2008)

4. Anonim. Berapa produksi dan luas lahan panen padi,, https://databoks.katadata.co.id accessed on 30 July 2018 
5. M. Le Troëdec, C. Peyratout, A. Smith, T. Chotard, Influence of various chemical treatments on the interactions between hemp fibres and a lime matrix, J Eur Ceram Soc, 29, 1861 (2009)

6. T.T. Nguyen, V. Picandet, S. Amziane, C. Baley, Influence of compactness and hemp hurd characteristics on the mechanical properties of lime and hemp concrete, Euro J Environ Civ Eng, 13, 1039 (2009)

7. T.T. Nguyen, V. Picandet, P. Carre, T. Lecompte, S. Amziane, C. Baley, Effect of compaction on mechanical and thermal properties of hemp concrete, Euro J Environ Civ Eng, 14, 545 (2010)

8. S.S. Julián, V.C. Janer, Materiales de construcción conpropriedades aislantes a base de cáscara de arroz. Informes de la Construcción, No 372, Institut des sciences de la construction Eduardo Torroja. Madrid, (1985)

9. R. Zerbino, G. Giaccio, G.C. Isaia, Concrete incorporating rice-husk ash without processing. Construction and Building Materials, 25, 371 (2011) 